\title{
P. Falzon (ed): Constructive Ergonomics
}

\author{
CRC Press, Boca Raton, 2015, 294 pp, \$71.96 (hardbound)
}

\author{
Bruce A. Barron
}

Published online: 17 January 2015

(C) Springer Science+Business Media New York 2015

Classically, ergonomics focused on the interface between workers and their work environments, including machines and work processes, to optimize employee health, safety, performance, and productivity. Constructive or developmental ergonomics is a relatively new concept whose goals are to reduce or eliminate ergonomic obstacles and maximize opportunities [1]. Falzon asserted that ergonomics should emphasize employee development in terms of knowledge and skill to optimize outcomes. Constructive Ergonomics and its contributing authors proffered a framework for this new model of ergonomics that incorporated facets of economic and management theory.

Constructive Ergonomics was organized into two sections: (1) resources and conditions for development and (2) dynamics of action and development. Section I focused on the development of employee skills, collective activities, psychosocial aspects of work, and organizational factors. Section II discussed interventions as dynamic processes, design and development of instruments, prevention of musculoskeletal disorders, project design, and other types of ergonomic analyses. Each chapter was logically organized, well-referenced, and written by experts in the field. Despite the book's organization and authoritative authors, the writing style was not conducive to understanding and learning. As a result, it was difficult to grasp basic principles and key concepts being proposed for this futuristic model of ergonomics. The proposed articulation between ergonomics, economics, and capability theory was neither fully developed nor thought applicable to realworld situations.

Constructive Ergonomics, which promoted an employee-centric model, may be a book ahead of its time. Although not recommended as a resource for ergonomists and other occupational health professionals engaged in workplace problems requiring immediate solutions; researchers and academicians in the field might find the book worthwhile since it provided new perspectives and advanced a number of unproven hypotheses. Even though developmental ergonomics is still in its infancy and its applicability to real-world scenarios is unknown, it is possible this new model could influence the future of ergonomics.

\section{Reference}

1. Falzon P. Constructive ergonomics, vol. viii. Boca Raton: CRC Press; 2015.

\footnotetext{
B. A. Barron $(\square)$

Division of Occupational and Environmental Medicine, University of Rochester School of Medicine and Dentistry, Rochester, New York

e-mail: bruce_barron@urmc.rochester.edu
} 